\title{
THE EFFECT OF PERCEIVED STRESS ON PSYCHOLOGICAL WELL-BEING WITH PROBLEM-FOCUSED COPING AS A MEDIATOR AMONG ENTREPRENEURS OF SMALL AND MEDIUM ENTERPRISES
}

\author{
Qamariyah Ratih Nurani \\ Department of Industrial and Organizational Psychology, Faculty of Psychology, \\ University of Airlangga, Surabaya, Indonesia \\ E-mail: ratih.nurani.qamariyah-2017@psikologi.unair.ac.id
}

\begin{abstract}
Entrepreneurship is associated with stressful situations, as entrepreneurial tasks are associated with income, risk, uncertainty and long working hours. Studies show that perceived stress is related to psychological well-being but the relationship between the two is ambiguous. Although it is widely accepted that stress is a fundamental part of entrepreneurship, there is little research that reveals how stress affects psychological condition of entrepreneurs and how its affects on the well-being and their businesses performances. Carnicer, et al. (2018) revealed that the effect of perceived stress on psychological well-being was shown to decrease if mediated by problem-focused coping. Therefore, this study investigates the role of problem-focused coping on mediating the effect of perceived stress and psychological well-being. Participants of this study were 105 entrepreneurs of small and medium enterprises (SMEs) from various regions in Indonesia. Data were collected using Perceived Stress Scale (Cohen \& Williamson, 1988), Brief COPE (Carver, 1997), and Psychological Well-Being Scale (Ryff, 1989). Overall, the findings of this study show that problem-focused coping plays a mediating role in the effect of perceived stress on psychological well-being.
\end{abstract}

\section{KEY WORDS}

Perceived stress, problem-focused coping, psychological well-being.

In recent years, interest in the study of well-being has been investigated in various fields, one of which is the field of entrepreneurship. These studies focus more on subjective well-being where this concept assumes that happiness and life satisfaction are the most important of human goals (Ryff, 1995). Individuals with high subjective well-being are considered to have high life satisfaction, high positive mood, and low negative mood (Diener, 1984). Meanwhile, the main aspects of psychological well-being received little attention, although this concept has greater relevance in the context of entrepreneurship.

Entrepreneurs tend to be associated with passionate individuals (Hahn et al, 2012), have high work involvement, strong motivations and are required to be able to recognize opportunities and respond to a very dynamic environment. This is closely related to the concept of psychological well-being where this idea is not only an outcome or a final condition, as the process of fulfilling or realizing one's identity, but is part of an individual's way of living a meaningful, growing and developing life (Ryff, 1995). Psychological well-being also reflects the way individuals work, manage relationships with others and facilitate individuals to experience variety of positive emotional experiences (Wiklund et al., 2019). Therefore, psychological well-being can be a source of fulfilling the principles of life, growth and self-development of entrepreneurs. With high psychological well-being, it is expected that entrepreneurs can produce high work productivity, work effectively and efficiently and be eager to maintain business goals so that they can provide positive change for the community (Wiklund et al., 2019).

Entrepreneurs are generally involved with dynamic task characteristics that make employers often experience higher levels of stress compared to employees in general (Buttner, 1992; Harris et al., 1999, in Uy, Foo \& Song, 2013). The way individuals accept and perceive stressors will affect the psychological condition of the individual. According to 
Sarafino (2008), if individuals perceive stressors negatively, it will affect the cognitive aspects of individuals and cause burnout, emotional fatigue, increased depersonalization, reduced self-fulfillment (Maslach, 1999, in Carnicer, et al., 2018) and decreased psychological wellbeing (Heiman, 2004; Struthers, Perry, \& Menec, 2000).

However, there are only few researches reporting the affects of stress to entrepreneur's psychological conditions and its impact on well-being and their business performances. Neuman and Fawcett (2002) revealed that it requires individual factors that can be activated after the stressor's invasion in order to protect individuals from the adverse effects of stress. Problem-focused coping can be one of the coping strategies which considered to be a buffer to maintain psychological adaptation during stressful conditions (Sonika, Shalini \& Kumar, 2019). Drnovsek, et al. (2010) reported that problem focusedcoping has a greater relationship to the personal well-being and business performance than any other types of coping. A study that conducted by Carnicer, et al. (2018) also revealed that problem-focused coping was proven to be able to mediate the relationship between perceived stress and psychological well-being.

Several studies have been conducted to examine the relationship between perceived stress and psychological well-being and its association with problem-focused coping, but there is still no mechanism underlying the relationship between the three, especially in the context of entrepreneurship. Strengthening psychological well-being among entrepreneurs is needed to be studied, especially at the SMEs's line that face future challenges in maintaining the country's current economic growth. By examining the predictors that can increase psychological well-being, individuals are expected to continue to work productively, get personal income, achieve career success and have good quality in their relationships and social networks.

\section{LITERATURE REVIEW}

One of the most widely used models of well-being was presented by Ryff (1989) and Ryff and Keyes (1995), describing well-being not simply as the attaining of pleasure, but as 'the striving for perfection that represents the realization of one's true potential'. Ryff's model is a multidimensional approach to the measurement of psychological well-being that taps six distinct aspects or facets: autonomy, personal growth, self-acceptance, purpose in life, environmental mastery, and positive relations with others. Taken together, these six dimensions describe well-being as condition where individuals have a positive attitude towards themselves and others, can make decisions and regulate their own behavior, create and regulate environments that are compatible with their needs, have a purpose in life and make their lives more meaningful, and try to explore and develop themselves.

Stress is the result of interactions between individuals and their transactional environment, meaning that stress arises because individuals interact with the environment, where the demands of the environment are perceived by individuals as dangerous or exceeding their abilities (Lazarus \& Folkman, 1984). Perception of stress occurs because the disruption of the individual's balance due to his inability to resolve problems or demands for adjustment to new circumstances or situations. Thus, if someone experiences a condition of the gap between the demands that must be generated in certain situations with the capacities and abilities possessed, then the individual can be said to be experiencing condition of stress.

Problem-focused coping is one of the coping strategies which more directed to the efforts to reduce the stressful demand of the situations (Lazarus \& Folkman, 1984). These efforts are directly focused to the stress sources and can be oriented to solve problems as effort to control the source of stress and also relieve stress by taking active action related to the stressful situation encountered. These efforts focus on problems solving, such as finding informations about an issue, gathering solutions that can be used as alternatives, considering alternatives in terms of costs and benefits, choosing alternatives, and undergoing the chosen alternative (Carver, et al., 1989). 


\section{CONCEPTUAL FRAMEWORK}

Based on the theoretical explanation that has been described, this study aims to examine the direct and the indirect effects of perceived stress on psychological well-being through problem-focused coping. Wolf (2016) states that although the situation in starting a business tends to be constrained by a variety of stressors, entrepreneurs are considered to be able to cope with it and survive with a prosperous life. Different results were found in the study of Strizhitkaya et al. (2018) where it is known that the effect of perceived stress on psychological well-being is not significant and an intervening variable that is able to mediate both variables is needed. Several studies have supported the statement by revealing that problem-focused coping has a significant effect on well-being (Uy, et al., 2013; Drnovsek, et al., 2010) and it also mediate both perceived stress and psychological well-being (Carnicer, et al., 2018). Therefore, the hypothesis of this study is perceived stress will not significantly influence psychological well-being and problem-focused coping will mediate the relationship between them.

\section{METHODS OF RESEARCH}

Participants of this study consist of 105 SME's entrepreneurs from several regions in Indonesia, with as much as $52,38 \%$ woman and $47,62 \%$ of men. The age of the participants varies between 20-35 years and dominated by by the entrepreneurs that occupied in food and beverages culinary for $40,9 \%$. The $59,1 \%$ are ranged in fashion, design, videography, photography, convection, printing and services.

Data obtained using survey methods using Perceived Stress Scale (Cohen \& Williamson, 1988) consists of 10 items with a reliability of 0.805 , a scale of Brief COPE (Carver, 1997) consists of 6 aitems problem-focused coping with reliability of 0,607 , and Psychological Well-Being Scale (Ryff, 1989) composed of 29 items with a reliability of 0.923. Data analysis was performed using the Partial Least Square analysis method with SmartPLS 3.0 software.

\section{RESULTS OF STUDY}

In this study, data were analyzed using structural model evaluation test. The structural model evaluation coefficient of R-square determination gives a result value of 0.368 for the variable psychological well-being which means that perceived stress and problem-focused coping can explain the $36,8 \%$ variance psychological well-being and the remaining $63.2 \%$ is explained by other factors outside the model. Problem-focused coping has an R-square coefficient of 0.068 which means that perceived stress is able to explain the $6,8 \%$ variance od problem-focused coping and the remaining $93.2 \%$ is explained by other factors outside the model. It can be concluded that there are still other factors outside the model that need to be considered related to the factors that affects psychological well-being among entrepreneurs.

Table 1 - Result of Structural Model Testing

\begin{tabular}{|c|c|}
\hline Endogenous Variable & $R^{2}$ \\
\hline PFC & 0,068 \\
\hline PWB & 0,368 \\
\hline
\end{tabular}

The result of the hypothesis testing shown by Table 2. Hypothesis 1 was accepted as there was no significant and direct effect between perceived stress and psychological wellbeing, $\beta=0,134, p$-value $>0.05$. Hypothesis 2 was accepted as problem-focused coping could have the role as a mediator between perceived stress and psychological well-being with $\beta=0,065$, $p$-value $<0,05$. 
Table 2 - Hypothesis Testing

\begin{tabular}{|c|c|c|}
\hline Model & $\beta$ & p-Value \\
\hline PS $\rightarrow$ PWB & $-0,134$ & 0,094 \\
\hline PS $\rightarrow$ PFC $\rightarrow$ PWB & $-0,065$ & 0,032 \\
\hline
\end{tabular}

\section{DISCUSSION OF RESULTS}

This study aims to examine and analyze the direct and indirect effects of perceived stress on psychological well-being with problem-focused coping as a mediator variable among entrepreneurs. In the entrepreneurship context, the impact of stress that negatively perceived will tend to decrease well-being, individual performance and business performance. Therefore, individual factors that can be activated after the appearance of the stressor are needed in order to protect individuals from the adverse effects of stress, one of which is through problem-focused coping.

The results of hypothesis 1 show that there are no direct effect of perceived stress on psychological well-being among the entrepreneurs. Thereby, the entrepreneurial perceptions of stress which generated by the environmental demands currently do not have a direct influence on entrepreneur's psychological well-being. To overcome stressful and unpredictable working environment conditions, entrepreneurs need an internal factor that is in themselves that can help changes the impact of stress from negative to positive side so that entrepreneurs can achieve a good psychological condition. If they can manage these stress conditions, they will be able to overcome the problems and survive with a prosperous life (Wolf, 2016). The results of this study are also in line with the research conducted by Strizhitkaya, et al. (2018) which revealed that the direct effect of perceived stress on psychological well-being is not significant and other variables that can reduce individual stress levels are needed.

Based on the result of hypothesis 2, the contribution given to perceived stress to psychological well-being through problem-focused coping is $6.5 \%$. This shows that problemfocused coping acts as a partial mediator because the effect of perceived stress on psychological well-being are significantly reduced when problem-focused coping variable was included. Although the amount of these contributions tends to be small, the decrease in the contribution indicates that problem-focused coping have a protective role on the effect of perceived stress on psychological well-being. Similar results were carried out by Carnicer, et al. (2018), where problem-focused coping plays a role in mediating the effect of perceived stress on psychological well-being in students in Barcelona. The application of problemfocused coping is considered to help individuals manage stress better and play a role in improving psychological well-being. In line with the results of the study, the effect of acquiring psychological well-being on entrepreneurs was also obtained from entrepreneurial orientation in solving problems when the entrepreneur encounter various stress conditions.

\section{CONCLUSION}

Overall, entrepreneurs in this study can still lead a meaningful, growing and developing life. The results showed that problem-focused coping tended to help entrepreneurs manage their psychological well-being. Problem-focused coping strategies can be done through a positive reevaluation of situations and conditions, making plans, as well as seeking advice or solutions to problems, which enable entrepreneurs to manage their personal and environmental resources. These strategies can have protective effects on stress and mediate the relationship between perceived stress and entrepreneur's psychological well-being.

With the limitations of generalizations in this study, further research is expected to replicate studies in samples that are more diverse in terms of geographical area. Further research can also consider other variables that act as a mediator in the influence between perceived stress and psychological well-being, such as perceived social support. Researchers can also consider other predictors that affect psychological well-being such as big five personality and psychological capital. Both of them can be resource protection 
factors that are activated following the invasion of stressors with the goals to protect the individuals from the adverse effects of stress, which aims to reduce harmful environmental conditions and increase the possibility of self-healing from the effects of stress so that the acquisition of psychological well-being is more likely to be obtained.

\section{REFERENCES}

1. Carnicer, J.G., Calderon, C., Batalla-Flores, A., \& Esteban-Bara, F. (2019). Role of coping responses in the relationship between perceived stress and psychological wellbeing in a sample of Spanish educational teacher students. Psychological reports, 122(2), 380-397.

2. Carver, C. S., Scheier, M. F., \& Weintraub, J. K. (1989). Assessing coping strategies: a theoretically based approach. Journal of personality and social psychology, 56(2), 267.

3. Carver, C. S. (1997). You want to measure coping but your protocol' too long: Consider the brief cope. International journal of behavioral medicine, 4(1), 92.

4. Cohen, S., \& Williamson, G. M. (1988). Perceived stress in a probability sample of the United States. In S. Spacapan \& S. Oskamp (Eds.), The social psychology of health: 3167. Newbury Park, CA: Sage.

5. Diener, E. (1984). Subjective well-being. Psychol. Bull. 95:542-75.

6. Drnovsek, M., Örtqvist, D., \& Wincent, J. (2010). The effectiveness of coping strategies used by entrepreneurs and their impact on personal well-being and venture performance. Faculty of Economics, Journal of Economics and Business, 28(2), 193-220.

7. Hahn, V. C., Frese, M., Binnewies, C., \& Schmitt, A. (2012). Happy and proactive? The role of hedonic and eudaimonic well-being in business owners' personal initiative. Entrepreneurship theory and practice, 36(1), 97-114.

8. Heiman, T. (2004). Examination of the salutogenic model, support resources, coping style, and stressors among Israeli university students. The Journal of Psychology, 138(6), 505-520.

9. Folkman, S., \& Lazarus, R. S. (1984). Stress, appraisal, and coping (pp. 150-153). New York: Springer Publishing Company.

10. Ryff, C.D. (1989). Happiness is everything, or is it? Explorations on the meaning of psychological well-being. J. Pers. Soc. Psychol. 57:1069-81.

11. Ryff, C.D. (1989). In the eye of the beholder: views of psychological well-being among middle-aged and older adults. Psychol. Ag- ing 4:195-210.

12. Ryff, C.D. (1995). Psychological well-being in adult life. Curr. Dir. Psychol. Sci. 4:99-104

13. Ryff, C. D. (2013). Eudaimonic well-being and health: Mapping consequences of selfrealization.

14. Sonika, S., \& Kumar, R. (2019). Resilience, Psychological Well-being, and Coping Strategies in Medical Students. Indian Journal of Psychiatric Nursing! Volume, 16(2).

15. Struthers, C. W., Perry, R. P., \& Menec, V. H. (2000). An examination of the relationships among academic stress, coping motivation and performance in college. Research in Higher Education, 41, 581-592.

16. Uy, M. A., Foo, M. D., \& Song, Z. (2013). Joint effects of prior start-up experience and coping strategies on entrepreneurs' psychological well-being. Journal of Business Venturing, 28(5), 583-597.

17. Wiklund, J., Nikolaev, B., Shir, N., Foo, M. D., \& Bradley, S. (2019). Entrepreneurship and well-being: Past, present, and future.

18. Wolf, I. (2016). Exploring the Stress and Coping Experiences of Early-Stage Entrepreneurs during the Venture Creation Process (Master's thesis, University of Twente). 